\title{
FLIP YOUR CLASS NOW;FLIPPED CLASSROOM MELALUI PENERAPAN MODEL PEMBELAJARAN EXO OLO TASK
}

\author{
Ditulis oleh : Dr. Nofrion, M. Pd \\ Dosen Program Studi Pendidikan Geografi \\ Email.dion_geografi@yahoo.com \\ Ponsel \& WA : 081363310550
}

\section{A. Pengantar Flipped Classroom}

Flipped classroom merupakan sebuah strategi dan metode pembelajaran membalikkan (flip) kondisi kelas konvensional. Jika dalam kondisi kelas konvensional, guru menyampaikan materi di dalam kelas lalu diikuti dengan penugasan di rumah maka pada flipped classroom ini, guru memberikan tugas kepada siswa untuk mempelajari materi yang akan dipelajari. Guru menyediakan video pembelajaran, bahan ajar, referensi dan lain-lain yang dapat mendukung guna mendapatkan pengetahuan dan modal awal sebelum belajar. J. Wesley Baker dari Universitas Cedarville bisa jadi merupakan orang pertama yang menggunakan istilah flip classroom. Lalu ada nama Alison King (1993). Kemudian Lage, Platt dan Treglia yang menerbitkan Inverting the Classroom: A Gateway to Creating an Inclusive Learning Environment (2000) serta Eric Mazur dari Harvard University yang menerbitkan Peer Instruction: A User's Manual. Tutorial tentang flipped classroom ini mulai dibuat oleh Jonathan Bergman dan Aaron Sams (2007).

Lebih detail, penjelasan tentang Flipped classroom dijelaskan sebagai "a method of instruction and form of blended learning. This model gets its name from the way it "flips" the traditional classroom model. Using this method, students watch videos or listen to lectures at home. When they come to class meetings, instructors facilitate group work and other activities that would typically be considered "homework."(www.learning-theories.com). Artinya, Flipped classroom merupakan sebuah metode pembelajaran dan bentuk dari "blended learning". Dalam model ini, siswa menonton video atau mendengarkan rekaman kuliah di rumah dan mendapatkan arahan tugas dan pokok-pokok masalah yang harus diperdalam dalam pertemuan nanti. Ketika mereka datang ke kelas, guru memfasilitasi kerja kelompok atau aktivitas belajar lain. Secara sederhana, operasional flipped classroom terlihat pada gambar berikut ini;

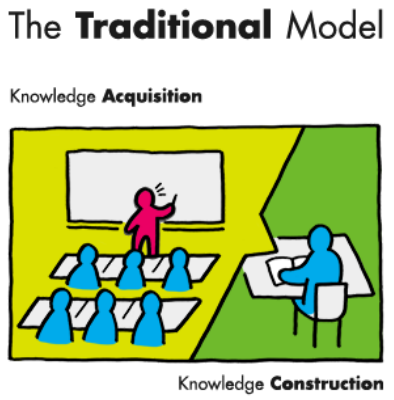

The Flipped Model

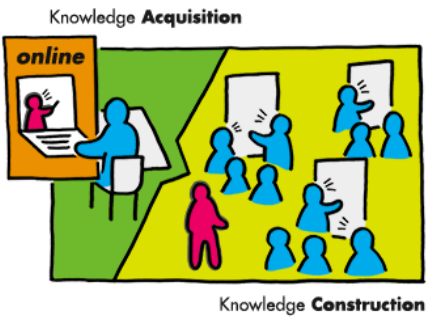

Gambar 1. Pola Pembelajaran Tradisional dan Flipped Model

Sumber : Flit, University of Tokyo

Pembelajaran Flipped Classroom memanfaatkan teknologi dengan dukungan fasilitas jaringan internet/daring sehingga siswa dapat menonton video, menyimak tutorial atau mendowload 
bahan-bahan pelajaran secara mandiri di rumah (Brent, 2013). flipped classroom menggunakan metode belajar yang menggunakan kegiatan kelompok, kolaborasi, pada kegiatan yang bersifat percobaan (Enfield, 2013). Betty Love et al(2014) yang menyatakan bahwa mahasiswa dapat belajar lebih banyak dengan model Flipped classroom daripada kuliah biasa. Nicola Sales (2013) yang mengungkapkan bahwa dengan model flipped classroom siswa mempunyai tanggung jawab pada pembelajaran mereka ketika mereka melihat video di rumah maupun saat pengorganisasian pembelajaran di kelas. Cara A. Marlowe (2012) dalam penelitiannya yang berjudulThe Effect Of The Flipped Classroom On Student Achievement And Stress menunjukkan bahwa efek dari flipped classroom dapat mengurangi tingkat stress mahasiswa dan nilai semester menunjukkan perbaikan.

Dari uraian di atas dapat disimpulkan bahwa model flipped classroom ini efektif untuk mempersiapkan siswa sebelum belajar. Dengan memiliki pengetahuan dan kemampuan awal (cognitive entry behaviour) mereka diharapkan lebih siap dan lebih interaktif dalam pembelajaran. Peran guru sebagai penyampai informasi (transfer of knowledge) semakin berkurang dan bergeser menjadi fasilitator pembelajaran melalui tugas-tugas dan rancanan aktivitas yang menatang. Tidak semua materi harus dijelaskan secara verbalis. Siswa sudah belajar di rumah melalui berbagai sumber dan media pembelajaran yang telah disiapkan guru. Hanya saja, dengan model ini guru diharapkan memiliki kemampuan dan literasi data dan teknologi serta ICT yang memadai serta memiliki kreatifitas tanpa batas.

\section{B. Mengenal Model Pembelajaran EXO OLO TASK}

Model Pembelajaran EXO - OLO TASK dikembangkan dalam Disertasi Nofrion (2019) untuk mengembangkan keterampilan berpikir tinggi siswa melalui penataan aktivitas belajar dan kolaborasi yang dipicu oleh dua jenis soal yaitu EXO TASK dan OLO TASK. Model pembelajaran ini terdiri dari empat sintak yaitu, 1) penguatan konsep (Strengthening Concept), 2) paket soal C1 - C3 atau (EXO TASK), 3) paket soal C4 - C6 atau OLO TASK dan 4) refleksi proses pembelajaran (Nofrion, 2019). Penguatan konsep dilakukan untuk mengetahui pengetahuan dan kemampuan awal siswa tentang materi yang akan dipelajari. Artinya, siswa telah ditugasi untuk membaca/mencari/mengelaborasi materi sebelum pembelajaran di kelas. Agar menarik, guru menggunakan teknik kata kunci. Guru menyiapkan kata-kata kunci yang ada di dalam lingkup materi lalu meminta siswa mencari arti kata kunci dan hubungan antar kata kunci. Sintak kedua yaitu EXO Task yaitu paket soal untuk pemanasan yang berisi soal-soal level C1, C2 dan C3 atau kategori LOTS dan MOTS. Siswa mengerjakan soal EXO secara berpasangan atau bisa juga sendiri tergantung kondisi yang terjadi. Sintak ketiga adalah OLO Task yaitu siswa diberikan soal-soal kategori HOTS atau soal-soal level C4, C5 dan C6. Secara berkelompok (4 orang/kelompok), siswa mengerjakan soal dan guru mendorong untuk terjadinya dialog, kolaborasi antar siswa. Refleksi adalah sintak terakhir dalam Model Pembelajaran EXO OLO Task (Nofrion, 2018; Nofrion et al, 2018). Tujuan Model Pembelajaran EXO OLO TASK ini adalah:

1. Mengembangkan aktivitas belajar siswa dalam pembelajaran baik aktivitas belajar dasar (basic learning activity) maupun aktivitas belajar lanjut (advance learning activity). 
2. Memfasilitas siswa untuk belajar secara individu, berpasangan dan berkelompok dalam rangka mengembangkan nilai-nilai dan sikap sosial diantara mereka.

3. Memberi ruang kepada siswa untuk berinteraksi dan berkolaborasi untuk mencapai keberhasilan dalam pembelajaran secara bersama dan berkelanjutan.

4. Melatih kemampuan guru dalam merancang soal LOTS, MOTS dan HOTS.

5. Mengembangkan keterampilan berpikir tingkat tinggi siswa.

Terlihat dari uraian tujuan Model Pembelajaran di atas bahwa Model Pembelajaran EXO OLO TASK ibarat pisau bermata dua karena berdampak kepada guru dan juga kepada siswa. Dampak terhadap guru adalah guru terbiasa dan terlatih menulis berbagai level soal terutama soal-soal HOTS. Hal ini diharapkan dapat meningkat kualitas guru karena peran guru berkontribusi di atas 50\% terhadap hasil belajar siswa (Hattie, 2008; Moursed et al, 2010; Pujiastuti et al, 2012). Sedangkan dampak bagi siswa adalah tumbuhnya dialog, interaksi dan kolaborasi antar siswa yang merupakan perwujudan "silent revolution" yang terjadi di dalam kelas (Sato, 2012).

Landasan teori dan konsep yang mendasari pengembangan sintak pembelajaran adalah; Tabel 1. Referensi Pendukung Sintak Model Pembelajaran EXO OLO TASK

\section{Sintak Model Pembelajaran Referensi Pendukung \\ EXO OLO TASK}

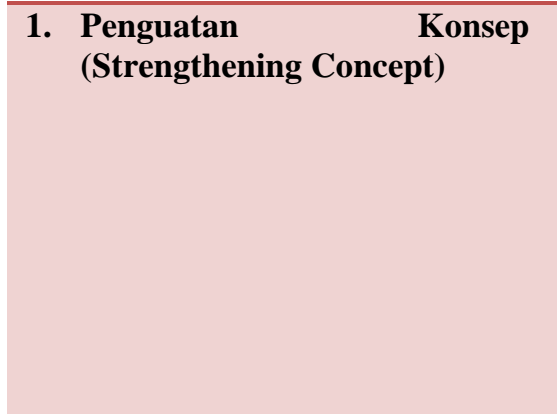

2. Examination Task/EXO Task

\section{Olympiad Task/OLO Task}

\section{Reflection}

Oriented
1. "Generative Learning" Learning" ((Slavin;1994, Jo Kemp et al;1994).

2. Ormrod (2008): aktivasi pengetahuan awal (prior knowledge activation) adalah proses mengingatkan peserta didik tentang hal-hal yang telah mereka ketahui yang berkaitan dengan topik baru merupakan upaya untuk mencapai pembelajaran bermakna (meaningfull learning).

3. Perhatian siswa akan meningkat melalui rancangan aktivitas khusus di kelas (Kanfer \& Kanfer, 1991;Schunk, 2012).

1. Pengetahuan dibangun oleh peserta didik melalui kontak dengan lingkungan, tantangan dan bahan yang dipelajari (Suparno, 2013).

2. Otak bekerja lebih baik jika membahas informasi dengan orang lain (Ruhl, Hughes dan Scholes (1987); Silbermen (2006).

Oriented 1. Soal yang sulit cara mendorong siswa untuk belajar asalkan masih dalam ZPD (Vygotsky, 1978;Sato, 2012).

2. Tindakan sosial yang dialami dimana siswa saling berbicara dan berkomunikasi membantu mereka dalam menyelesaikan suatu masalah (Gerlach, J. M., 1994 \& Laal, Laal., 2012).

3. Tugas yang menantang adalah salah satu ciri pembelajaran yang efektif (Silbermen, 2006).

4. Dialog kelas sangat bermanfaat bagi pendidik, karena dengan memonitor komentar ataupun pertanyaan mereka secara cermat, pendidik dapat mengidentifikasi dan menyelesaikan yang bisa menghambat kemampuan mereka untuk memperoleh pengetahuan dan keterampilan yang lebih luas lagi. (Presseisen, dkk, 1994, (dalam Ormrod, 2008)

1. Peninjauan, penilaian diri akan membantu menciptakan belajar sebagai kegiatan yang tidak terlupakan (Silbermen, 
Sedangkan uraian pelaksanaan pembelajaran berupa kegiatan guru dan kegiatan siswa dijelaskan pada tabel berikut ini;

Tabel 2. Uraian Sintak Pembelajaran dan Gambaran Kegiatan Siswa dan Guru dalam Model Pembelajaran EXO OLO TASK

\begin{tabular}{ccc}
\hline No & $\begin{array}{c}\text { Sintak/Tahap-tahap } \\
\text { Pembelajaran }\end{array}$ & Uraian Kegiatan Pembelajaran \\
\hline
\end{tabular}

Menelusuri pengetahuan awal siswa, memberikan penguatan dan memastikan bahwa siswa telah memiliki pengetahuan awal yang memadai dengan menggunakan Teknik Kata Kunci.

\section{KEGIATAN GURU;}

1. Menugaskan siswa untuk mencari dan membaca materi (sebelum belajar di kelas).

2. Mempraktikan Teknik Kata Kunci untuk mengetahui pengetahuan awal siswa.

$1 \quad$ Kunci

(Concept

Strengthening)

3. Mengelola aktivitas belajar berupa aktivitas individu

4. Memberikan penguatan.

\section{KEGIATAN SISWA;}

1. Mencari dan membaca materi.

2. Mencari arti kata kunci dan hubungan antar kata kunci.

3. Menyampaikan temuan atau hasil pencarian kata kunci

4. Menanyakan materi yang belum dipahami.

5. Menyimak penguatan yang disampaikan guru.

Mengembangkan landasan kemampuan berfikir tingkat tinggi siswa berupa LOTS dan MOTS.

KEGIATAN GURU;

1. Mengelola kegiatan belajar dalam bentuk aktivitas berpasangan.

2. Memberikan paket soal EXO (C1-C3).

3. Mengobservasi pembelajaran.

EXO TASK 4. Memberikan bantuan (scaffolding) sesuai kebutuhan.

(Soal Kategori LOT 5. Menyajikan penjelasan dan penguatan.

2 dan MOTS)

Examination Oriented Task

$\begin{array}{cc} & \\ & \\ & \text { OLO TASK } \\ & \text { (Soal Kategori HOTS) } \\ & \text { Olympiad Oriented } \\ & \text { Task }\end{array}$

\section{KEGIATAN SISWA;}

1. Mengerjakan soal dengan pasangan masing-masing.

2. Mendiskusikan dan Menyajikan hasil temuan.

3. Menanyakan soal yang belum dipahami (kepada pasangan atau pasangan lain).

4. Berdialog

Mengembangkan Keterampilan Berfikir Tingkat Tinggi/HOTS Siswa.

\section{KEGIATAN GURU;}

1. Menempatkan siswa dalam kelompok (4 orang/kelompok).

2. Memberikan soal OLO (C4-C6)

3. Mengobservasi pembelajaran

4. Memberikan bantuan (scaffolding) sesuai kebutuhan.

5. Menjadikan penjelasan dan penguatan.

KEGIATAN SISWA;

1. Mengerjakan soal dalam kelompok. 
2. Mendiskusikan dan menyajikan temuan

3. Menanyakan soal yang belum dipahami (dalam kelompok atau antar kelompok).

4. Berdialog dan berkolaborasi

Peninjauan perkembangan diri dan refleksi pembelajaran.

\section{KEGIATAN GURU;}

4

Refleksi

Reflection

1. Memfasilitasi siswa untuk melakukan refleksi proses pembelajaran dengan format 3-2-1 (TWC).

2. Memberikan penguatan.

KEGIATAN SISWA;

1. Menyampaikan hasil peninjauan perkembangan diri dan refleksi pembelajaran.

Secara umum profil Model Pembelajaran EXO OLO TASK dapat dicermati melalui gambar berikut ini;

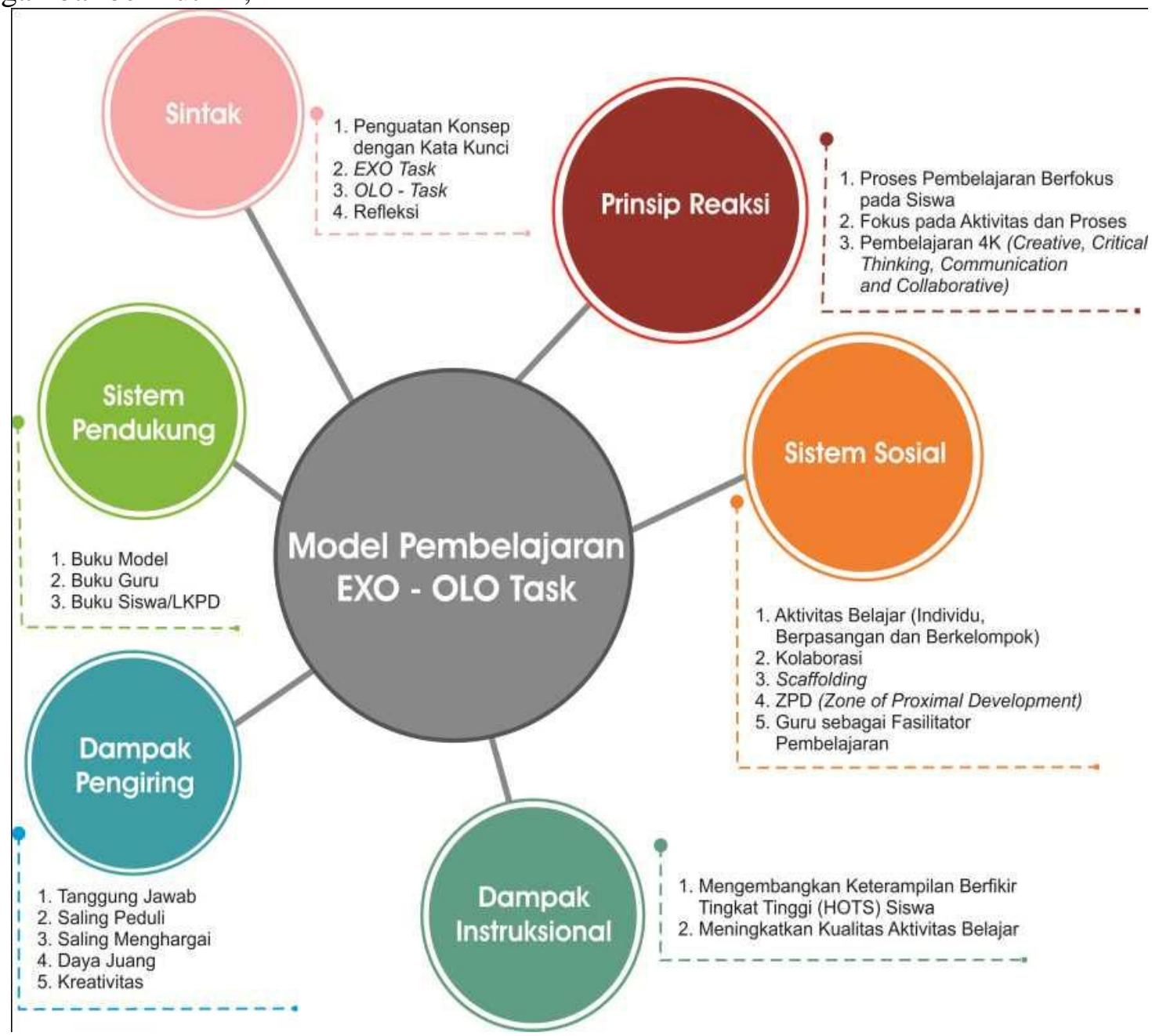

Gambar 2. Profil Model Pembelajaran EXO OLO TASK

Sumber : Nofrion $(2018,2019)$ dan Nofrion et al (2018) 


\section{Kolaborasi Flipped Classroom dengan Model Pembelajaran EXO OLO TASK}

Flipped classroom adalah strategi pembelajaran yang menyediakan berbagai sumber belajar untuk diakses siswa sebelum pembelajaran. Dengan strategi ini, siswa masuk kelas tidak lagi dengan kepala kosong dan juga bisa sebagai solusi bagi siswa karena satu dan lain hal tidak hadir pada satu pertemuan. Sedangkan Model Pembelajaran EXO OLO TASK juga memberikan penugasan kepada siswa untuk mempelajari materi yang akan dipelajari. Bedanya, pada flipped classroom, sumber belajar difokuskan pada sumber belajar berbasis ICT seperti video, video tutorial praktikum dan lain-lain, pada Model Pembelajaran EXO OLO Task tidak dinyatakan dengan tegas. Namun, dalam model EXO OLO TASK, siswa harus mempelajari (dengan cara apapun) materi yang akan dipelajari. Pada flipped classroom, pembelajaran lebih fokus kepada Project Based Learning/PjBL maka pada Model Pembelajaran EXO OLO Task memiliki sintak sendiri.

Berdasarkan karakteristik flipped classroom dan Model Pembelajaran EXO OLO TASK tersebut maka guru bisa menggabungkan keduanya dalam satu pembelajaran. Terutama pada materi-materi yang tidak berbasis proyek. Operasionalnya, guru menerapkan Flipped Classroom pada pra pembelajaran dengan menyediakan berbagai sumber dan media pembelajaran yang bisa diakses oleh siswa secara daring. Lalu, untuk pembelajarannya, guru menggunakan Model Pembelajaran EXO OLO TASK dengan empat sintaknya.

\section{DAFTAR RUJUKAN}

Betty Love, Angie Hodge, Neal Grandgennet and AndrewW. Swift. 2014. Student Learning and Perceptions in a Flipped Linear Algebra Course. International Journal of Mathematic Education in Science and Tecnology.Vol 45, No. 3, pp 317-324. Francis.

Bergman, J., A. Sams. 2012. Flip Your Classroom: Reach Every Student in Every Class Every Day. United States: The International Society

Cara A. Marlowe. 2012. The Effect Of The Flipped Classroom On Student Achievement And Stress. Montana: Montana State University.

Hamalik, Oemar. 2012. Pendekatan Baru Strategi Mengajar Berdasarkan CBSA. Bandung. Sinar Baru Algensindo

Hattie, John. 2008. "Validating the Specification of Standards for Teaching: Application to the National Board for Professional Teaching Standard' Assessment" in Lawrence Ingwarson \& John Hettie (eds). Assessing Teachers for Professional Certification: The First Decade of National Board for Professional Teaching Standards. Howard House, Wagen Lane, UK: Emerald Group Publishing Ltd. 
Johnson, Graham Brent. 2013. Student Perceptions Of The Flipped Classroom. Columbia: The University Of British Columbia.

Jacob Enfield. 2013. Looking at the impact of the Flipped Classroom Model of Instruction on Undergraduate Multimedia Student at CSUN. TechTrends. Vol 57. No. 6 pp. $14-18$

Mourshed, M., Chijioke, C., \& Barber, M. (2010). How the world's most improved school systems keep getting better. New York: McKinsey \& Company

Nicola Sales. Flipped the Classroom : Revolutionising Legal Research Training. Cambridge Journals. Vol. 13. Pp 231-235

Nofrion, N. (2018, October 14). PANDUAN PELAKSANAAN MODEL PEMBELAJARAN EXO OLO TASK (MENGEMBANGKAN KETERAMPILAN BERPIKIR TINGKAT TINGGI (HOTS) DALAM PEMBELAJARAN). https://doi.org/10.31227/osf.io/wh2mp

Nofrion, N. (2018, October 14). KARAKTERISTIK PEMBELAJARAN GEOGRAFI ABAD 21. https://doi.org/10.31227/osf.io/kwzjv

Nofrion, N. (2019, May 1). Panduan Praktis Implementasi Model Pembelajaran EXO OLO TASK. https://doi.org/10.31227/osf.io/an7xj

N Nofrion et al. 2018. IOP Conf. Ser.: Earth Environ. Sci.145 012038

Pujiastuti, Eko, Tri Joko Raharjo dan A. Tri Widodo. 2012. "Kompetensi Profesional, Pedagogik Guru IPA, Persepsi Siswa tentang Proses Pembelajar-an dan Kontribusinya terhadap Hasil Belajar di SMP/MTs Kota Banjar Baru" di dalam Innovative Journal of Curriculum and Educational Technology Vol. 1 No. 1. Tahun 2012 (http://journal.unnes.ac.id/sju/index.php/ujet)

Roehl, Amy, Shweta Linga dkk. 2013. The Flipped Classroom: An Opportunity To Engage Millennial Students Through Active Learning Strategies. Texas : Christian University Jurnal Internasional Vol. 105. No. 2. 2013 JFCS.

Shimamoto, Dean N. 2012. Implementing a Flipped Classroom: An Instructional Module. Hawai Amerika Serikat: Department of Educational Technology University of Hawaii Manoa.

Wesley Baker. 2013. Flipping the Classroom : Revolutionising Legal Research Training. Cambridge Journal. Vol 13, pp 231-235.

www.esaiedukasi.com 